\title{
Emerging species in pediatrics: a case of Acinetobacter johnsonii meningitis
}

\author{
Mónica P. Gutiérrez-Gaitán ${ }^{1,2 *}$, Andrés D. Montoya-Moncada ${ }^{3}$, José M. Suescún-Vargas ${ }^{1,3,4,5}$, \\ Javier Y. Pinzón-Salamanca ${ }^{1,3,4,5}$, and Brianna L. Aguirre-Borrero ${ }^{1,3}$
}

${ }^{1}$ Departamento de Pediatría, Instituto Roosevelt, Bogotá; ${ }^{2}$ Facultad de Medicina, Universidad del Bosque, Bogotá; ${ }^{3}$ Departamento de Pediatría, Escuela de Medicina y Ciencias de la Salud, Universidad del Rosario, Bogotá; ${ }^{4}$ Departamento de Pediatría, Facultad de Medicina, Universidad de los Andes, Bogotá; ${ }^{5}$ Departamento de Pediatría, Facultad de Medicina, Universidad de la Sabana, Cundinamarca. Colombia

\begin{abstract}
Background: Among the microorganisms corresponding to the genus Acinetobacter, Acinetobacter johnsonii is a species of low epidemiological incidence compared to Acinetobacter baumannii. However, it has a comparable infectious capacity since it can be involved in severe diseases like bacteremia or meningitis. Its habitat is variable, usually found in humid tropical climates (as is the case in Colombia), soil, water, or animal reservoirs. It is still an unknown germ for most health personnel, as there are not many reported cases, and information about its microbiological and epidemiological characteristics is still scarce, making its identification and treatment difficult. Clinical case: We describe the case of $A$. johnsonii infection of the central nervous system in a 15-year-old female, as well as the diagnostic method used, the course of the disease, medical management, and clinical outcome. Conclusions: It is of utmost importance to report this type of microorganisms to facilitate early diagnosis and appropriate treatment. More scientific publications of this type are needed to broaden the knowledge about these microorganisms.
\end{abstract}

Keywords: Acinetobacter spp. Meningitis. Cerebrospinal fluid.

\section{Especies emergentes en pediatría: a propósito de un caso de meningitis por Acinetobacter johnsonii}

\section{Resumen}

Introducción: Dentro de los microorganismos correspondientes al género Acinetobacter, Acinetobacter johnsonii es una especie de poca frecuencia epidemiológica en comparación con Acinetobacter baumannii. Sin embargo, posee una capacidad infecciosa equiparable, ya que se puede ver involucrado en patologías graves, como bacteriemia o meningitis. Su hábitat es variable y suele encontrarse en climas tropicales húmedos (como es el caso de Colombia), suelos, aguas o reservorios animales. Actualmente sigue siendo un patógeno desconocido por gran parte del personal de salud, pues no existen muchos casos reportados, y la información acerca de sus características microbiológicas y epidemiológicas aún es escasa, lo que dificulta su identificación y tratamiento. Caso clínico: Se describe una infección del sistema nervioso central por A. johnsonii en una paciente de sexo femenino de 15 años, así como el método diagnóstico utilizado, el curso de la

\section{Correspondence:}

*Mónica P. Gutiérrez-Gaitán

E-mail: moni18gutierrez@gmail.com

Available online: $24-01-2022$

Date of reception: 28-02-2021

Date of acceptance: 25-05-2021

DOI: 10.24875/BMHIM.21000041
Bol Med Hosp Infant Mex. 2022;79(1):51-55

www.bmhim.com

1665-1146/@ 2021 Hospital Infantil de México Federico Gómez. Published by Permanyer. This is an open access article under the CC BY-NC-ND license (http://creativecommons.org/licenses/by-nc-nd/4.0/). 
enfermedad, el manejo médico y el desenlace clínico. Conclusiones: Es de suma importancia dar a conocer la existencia de estos microorganismos para facilitar el diagnóstico temprano y el tratamiento apropiado. Se requieren más publicaciones científicas de este tipo para ampliar el conocimiento acerca de estos microorganismos.

Palabras clave: Acinetobacter spp. Meningitis. Líquido cefalorraquídeo.

\section{Introduction}

The genus Acinetobacter (from the Greek $\alpha \kappa i v \varepsilon \tau 0 \sigma$ [akinetos], immotile) ${ }^{1}$ belongs to the family Moraxellaceae ${ }^{2}$, a group of Gram-negative, non-fermenting, strictly aerobic, catalase-positive, oxidase-negative coccobacilli ${ }^{3}$. This species has gained significant importance in recent years due to its high virulence and rapid resistance to broad-spectrum antibiotics, which places it as a growing cause of morbidity and mortality from outbreaks of healthcare-associated infections (HAls), especially in Latin America ${ }^{4}$. In contrast, Acinetobacter spp. genospecies have been described in community-acquired infections, including natural disasters and wars, which has attracted interest from different researchers ${ }^{5}$.

More than 40 genospecies are currently known and have been identified by molecular techniques since their isolation is difficult by biochemical tests ${ }^{6}$. Of these species, Acinetobacter baumannii (genomic species 2) has been the most isolated and with the most significant clinical impact, and therefore the subject of more studies. Additionally, using DNA-DNA hybridization processes, other species have been defined, including Acinetobacter johnsonii (genomic species 7) ${ }^{3}$. This genospecies was first described by Bouvet and Grimont in 1986 and named after the American bacteriologist John L. Johnson ${ }^{7}$. This microorganism has an isolation incidence of $1.7-2.0 \%$ in adult and pediatric patients, with a marked difference compared to $A$. baumannii, which reaches $78-90 \% 8,9$.

A. johnsonii is characterized by optimal growth at $15-30^{\circ} \mathrm{C}$ and no growth at $37^{\circ} \mathrm{C}$, an incubation period of 1-2 days, catalase-positive, cytochrome oxidase negative, and producing gamma hemolysis ${ }^{10}$. It inhabits humid climates, specifically soil, pure and wastewater, and animal reservoirs such as pets and arthropods. In humans, some studies have described the isolation of A. johnsonii in the gastrointestinal tract, skin wounds, chronic rhinosinusitis, endocarditis ${ }^{2,6}$, catheter-related bloodstream infections, and peritoneal dialysis-associated peritonitis ${ }^{6}$. A. johnsonii was the predominant Acinetobacter species in fecal samples from healthy individuals in the Netherlands (17.5\%) ${ }^{1}$.
The most frequent clinical manifestations of infection by this genus are bacteremia and pneumonia associated with mechanical ventilation ${ }^{11}$ and soft tissue infection, urinary tract infection, endocarditis, and meningitis. The latter is significant since it has a high incidence in the pediatric population ${ }^{12}$. In this report, we describe the clinical case of a pediatric patient who developed bacterial meningitis with isolation of $A$. johnsonii in cerebrospinal fluid culture.

\section{Clinical case}

We present the case of a 15 -year-old female patient who consulted for global headache and fever of 11 days, for which she received antipyretic treatment at home. She first went to a primary care institution, where migraine was suspected; the patient was later discharged with analgesic treatment. However, due to the persistence of symptoms and appearance of emesis, blurred vision, and diplopia, she was hospitalized for a specialized examination. As background, the patient was the product of a full-term pregnancy with adequate control and had a complete vaccination schedule. She presented with dengue hemorrhagic fever at 14 years of age. On admission, the patient presented with Glasgow 15/15 with generalized weakness, although with selective bilateral motor control of the neck in a standing position, good symmetrical reflexes, no Babinski's sign or clonus. The patient could stand upright with head instability, head bobbing, gait instability, horizontal nystagmus on extreme gaze, and $3 / 5$ strength in the lower limbs. A simple cerebral axial computed tomography and nuclear magnetic resonance contrasted with cerebral venography were performed, showing the left transverse sinus hypoplasia as a normal anatomical variant. Blood count, liver function, amylase, urinalysis, and human chorionic gonadotropin hormone beta fraction ( $\beta$-hCG) studies were normal, and polymerase chain reaction (PCR) test for SARS-CoV-2 was negative. Given the high suspicion of neuroinfection and infectious cerebellitis, a lumbar puncture was performed, reporting 100\% pleocytosis, with increased neutrophils, hypoglycorrhachia, and hyperproteinorrhachia. Antibiotic treatment ceftriaxone 
and vancomycin was started. Chinese ink staining, Filmarray® meningitis/encephalitis panel, and VDRL (Venereal Disease Research Laboratory) serum and cerebrospinal fluid cytochemistry were negative. After the first 24 hours of cerebrospinal fluid incubation, growth of Gram-negative germs was documented, and vancomycin was discontinued. On the sixth day, cerebrospinal fluid culture was obtained, reporting isolation of multi sensitive $A$. johnsonii (Table 1), leading to a change in antibiotic treatment to ampicillin sulbactam. The final diagnosis of $A$. johnsonii meningoencephalitis was concluded. On the eighth day of antibiotic treatment, the patient presented two febrile peaks associated with bilateral retro-ocular pain and mild frontal headache. Therefore, in search of an additional focus, a complete blood count, chest X-ray, and blood cultures were performed again, with negative results for new findings. Subsequently, the dysthermia resolved spontaneously after 2 days, with febrile symptoms considered within the clinical framework of the current pathology. On day 14, the patient could not walk, with paresthesia and sensory alteration to temperature sensation in the right palmar region, without compromise of strength in the extremities, so peripheral neuropathy was suspected. A nerve conduction test was indicated, finding the right ulnar nerve entrapment at the elbow. The clinical picture of paresthesias, together with the results found in the nerve conduction test, were related to the entrapment, so it was considered an incidental finding that could not be related to the current meningoencephalitis. The control simple and contrasted brain magnetic resonance imaging study was reported within normal limits. On day 18 of treatment, a control lumbar puncture was performed. The cerebrospinal fluid cytochemical study showed the expected results for resolution of meningitis, no pleocytosis, scarce and fresh red blood cells secondary to puncture, ascending hypoglycorrhachia, normal protein concentration, and Gram without microorganisms. After completing 21 days of antibiotic treatment, the patient was discharged, followed by a physical rehabilitation program, improving her gait pattern without antibiotic prophylaxis and multidisciplinary follow-up.

\section{Discussion}

Bacterial meningitis in pediatric patients is a disease of significant morbidity that can generate considerable complications and neurodevelopmental alterations. In terms of etiology, Gram-negative bacilli are responsible for one-fifth of the cases of meningitis in this
Table 1. Antibiogram of the isolated Acinetobacter johnsonii strain

\begin{tabular}{|l|c|l|}
\hline \multicolumn{3}{|l|}{ Culture of Acinetobacter johnsonii } \\
\hline Antibiotic & MIC & Interpretation \\
\hline Ampicillin/Sulbactam & $\leq 2$ & Susceptible \\
\hline Cefepime & 8 susceptible & Susceptible \\
\hline Ceftazidime & 8 susceptible & Susceptible \\
\hline Ceftriaxone & 8 susceptible & Susceptible \\
\hline Ciprofloxacin & $\leq 1.0$ & Susceptible \\
\hline Gentamicin & $\leq 4$ & Susceptible \\
\hline Meropenem & $\leq 1.0$ & Susceptible \\
\hline Piperacillin/tazobactam & $\leq 16$ & Susceptible \\
\hline Tigecycline & $\leq 1.0$ & Susceptible \\
\hline $\begin{array}{l}\text { Trimethoprim/ } \\
\text { sulfamethoxazole }\end{array}$ & $\leq 1$ & Susceptible \\
\hline
\end{tabular}

MIC, minimum inhibitory concentration.

population ${ }^{11}$. According to the systematic review by $\mathrm{Hu}$ et al., neuroinfection is one of the most common presentations of pediatric Acinetobacter infection ${ }^{12}$.

Most infections caused by this microorganism have been described as HAls, with $A$. baumannii as the main microorganism and a higher prevalence in neonates and children under 10 years of age ${ }^{13,14}$. The most frequently reported risk factors include neurosurgical procedures $^{13}$, head trauma, intracranial hemorrhage ${ }^{11}$, bacteremia ${ }^{13}$, cerebrospinal fluid leakage, foreign body implantation ${ }^{14}$, and recent antibiotic administration. However, isolation of Acinetobacter in community-acquired infections is rare, with very few reports in the literature, which have occurred more frequently in patients with no comorbidities and no risk factors. In addition, other genospecies such as $A$. johnsonii ${ }^{6}, A$. calcoaceticus, and $A$. rufi are mainly sensitive to antimicrobials in different clinical trials, unlike $A$. baumannii, which is usually highly resistant ${ }^{14}$.

The clinical manifestations of Acinetobacter neuroinfection are similar to those described for meningitis caused by other microorganisms. Most patients present with fever, seizures, signs of meningeal irritation, focal manifestations, emesis, and headache, as observed in the present case $^{14}$. Given the clinical suspicion of an intracranial infectious process and the lack of specificity of blood test findings, lumbar puncture is of great importance in diagnosing this condition. Therefore, the 
cerebrospinal fluid analysis should include the determination of proteins, glucose, cell count, and Gram stain. Typical findings include the presence of pleocytosis with neutrophilic predominance, hyperproteinemia, and hypoglycorrhachia ${ }^{4,5}$. The gold standard is cerebrospinal fluid culture for isolation of the infecting microorganism.

The treatment of neuroinfection caused by the genus Acinetobacter represents a challenge for the clinician, given the increasing antimicrobial resistance reported and the fact that most antibiotics have a low permeability at the blood-brain barrier, thus reducing the possibilities of treatment ${ }^{15}$. The state of antibiotic multidrug resistance of $A$. baumannii due to the irrational use of antibiotics in patients carrying resistance genes has been widely described ${ }^{16}$. A marked sensitivity pattern has been evidenced in other genospecies such as A. johnsonii, which is consistent with the antibiogram of the present case, which allowed a de-escalation of the initial empirical management.

According to the above, the local resistance pattern of the microorganisms causing meningitis in pediatric patients should be considered when deciding on empirical antibiotic therapy, which should be intravenous and broad-spectrum, initially covering Gram-positive and Gram-negative microorganisms. As for the coverage of Gram-negative bacteria, a broad-spectrum cephalosporin, a beta-lactam with a beta-lactamase inhibitor, or a carbapenem should be selected, depending on the local resistance pattern, while awaiting the antibiogram susceptibility pattern ${ }^{17}$. Finally, it is worth mentioning the high mortality rates documented in neuro infections due to Acinetobacter spp., which reach more than $50 \%$ in pediatric patients ${ }^{9,13}$, with higher mortality in post-surgical patients ${ }^{17}$. Furthermore, neurological complications and sequelae are frequent (61\%) in surviving patients ${ }^{18}$, as in our case, which occurred, albeit mildly.

Compared to $A$. baumannii, A. johnsonii has not been the subject of many clinical studies. Even so, its clinical importance has increased in recent years due to the increase in potentially severe infections in pediatric patients, most frequently associated with bacteremia and meningitis. Given the increasing variety of Acinetobacter species and their presence in the environment and the hospital setting, early recognition of their clinical spectrum is of great importance for a rapid and accurate diagnosis that allows timely and essential treatment considering the high morbimortality of the pathological processes that these microorganisms could generate. In addition, further research is needed to determine new Acinetobacter species in the region and local resistance patterns.

\section{Ethical disclosures}

Protection of human and animal subjects. The authors declare that no experiments were performed on humans or animals for this study.

Confidentiality of data. The authors declare that they have followed the protocols of their work center on the publication of patient data.

Right to privacy and informed consent. The authors have obtained the written informed consent of the patients or subjects mentioned in the article. The corresponding author has this document.

\section{Conflicts of interest}

The authors declare no conflict of interest.

\section{Funding}

None.

\section{Acknowledgments}

We thank Dr. Freddy G. Soto, pediatric infectious disease specialist at the Roosevelt Institute, for his excellent management, commitment, and patient follow-up.

\section{References}

1. Hernández Torres A, García Vázquez E, Yagüe G, Gómez Gómez J Acinetobacter baumanii multirresistente: situación clínica actual y nuevas perspectivas. Rev Esp Quimioter. 2010;23:12-9.

2. Rada Cuentas J. Acinetobacter, un patógeno actual. Rev Bol Ped. 2016;55:29-48.

3. Vanegas-Múnera JM, Roncancio-Villamil G, Jiménez-Quiceno JN. Acinetobacter baumannii: importancia clínica, mecanismos de resistencia y diagnóstico. Rev CES Med. 2014;28:233-46.

4. Correa AG. Acinetobacter. In: Cherry J, Demmler-Harrison GJ, Kaplan SL, Steinbach WJ, Hotez PJ, editors. Feigin and Cherry's Textbook of Pediatric Infectious Diseases. Amsterdam: Elsevier; 2019. pp. 1124-8.

5. Kanafani ZA, Kanj SS. Acinetobacter infection: epidemiology, microbiology, pathogenesis, clinical features, and diagnosis. Up to date; 2020. Available from: https://www.uptodate.com/contents/acinetobacter-infection-epidemiology-microbiology-pathogenesis-clinical-features-and-diagnosis.

6. Rodríguez $\mathrm{CH}$, Nastro M, Dabos L, Vay C, Famiglietti A. Frecuencia de aislamiento y resistencia a los antimicrobianos de Acinetobacter spp. recuperadas de pacientes atendidos en un hospital universitario de la Ciudad Autónoma de Buenos Aires, Argentina. Rev Argent Microbiol. 2014;46:320-4.

7. Bouvet $\mathrm{P}$, Grimont $\mathrm{P}$. Taxonomy of the genus Acinetobacter with the recognition of Acinetobacter baumannii sp. nov., Acinetobacter haemolyticus sp. nov., Acinetobacter johnsonii sp. nov., and Acinetobacter junii sp. nov. and emended descriptions of Acinetobacter calcoaceticus and Acinetobacter Iwoffii. Int J Syst Evol Microbiol. 1986;36:228-40.

8. Turton JF, Shah J, Ozongwu C, Pike R. Incidence of Acinetobacter species other than $A$. baumannii among clinical isolates of Acinetobacter: evidence for emerging species. J Clin Microbiol. 2010;48:1445-9. 
9. Santisteban Larrinaga $Y$, Carmona Cartaya $Y$, Pérez Faria $Y$, Díaz Novoa L, García Giro S, Kobayashi N, et al. Infecciones por los géneros Klebsiella y Acinetobacter en hospitales pediátricos cubanos y resistencia antibiótica. Rev Cubana Med Trop. 2014:66:400-14.

10. Podstawka A. Acinetobacter johnsonii. Braunschweig: BacDive; 2020 Available from: https://bacdive.dsmz.de/pdf-view/8088?doi=doi\%3A10.13145\%2Fbacdive8088.20201210.5

11. Kanafani ZA, Kanj SS. Acinetobacter infection: epidemiology, microbiology, pathogenesis, clinical features, and diagnosis. Up to date; 2020 Available from: https://www.uptodate.com/contents/acinetobacter-infection-epidemiology-microbiology-pathogenesis-clinical-features-and-diagnosis

12. Hu J, Robinson J. Systematic review of invasive Acinetobacter infections in children. Canadian J Infect Dis Med Microbiol. 2010;21:83-8.

13. Chang WN, Lu CH, Huang CR, Chuang YC. Community-acquired Acinetobacter meningitis in adults. Infection. 2000;28:395-7.
14. Xiao J, Zhang C, Ye S. Acinetobacter baumannii meningitis in children: a case series and literature review. Infection. 2019;47:643-9.

15. Saleem AF, Shah MS, Shaikh AS, Mir F, Zaidi AK. Acinetobacter species meningitis in children: a case series from Karachi, Pakistan. J Infect Dev Ctries. 2011;5:809-14.

16. Castillo-Ramírez S, Mateo-Estrada V, Gonzalez-Rocha G, Opazo-Capurro A. Phylogeographical analyses and antibiotic resistance genes of Acinetobacter johnsonii highlight its clinical relevance. 2020;5:e00581-20.

17. Kanafani ZA, Kanj SS. Acinetobacter infection: treatment and prevention. Up to date; 2020. Available from: https://www.uptodate.com/contents/ acinetobacter-infection-treatment-and-prevention\#: :text=When\%20infections $\% 20$ are $\% 20$ caused $\% 20$ by,eg\%2C $\% 20$ imipenem $\% 2$ C $\% 20$ meropenem $\% 2 \mathrm{C} \% 20$ or

18. Chen SF, Chang WN, Lu CH, Chuang YC, Tsai HH, Tsai NW, et al. Adult Acinetobacter meningitis and its comparison with non-Acinetobacter Gram-negative bacterial meningitis. Acta Neurol Taiwan. 2005;14:131-7. 